\title{
Cavitation Erosion Resistance Tests Performed on Some Stainless Steels for Turbine Runner Blades
}

\author{
GEORGE COMAN ${ }^{1}$, MIRCEA CRISTIAN PANTILIMON ${ }^{1}$, MIRELA GABRIELA SOHACIU ${ }^{1}$, SORIN CIUCA ${ }^{2}$, MARIUS GABRIEL ANTON ${ }^{1}$, \\ CRISTIAN PREDESCU ${ }^{1}$, RUXANDRA ELENA DUMITRESCU ${ }^{2}$, ANDREI CONSTANTIN BERBECARU ${ }^{1 *}$, IOANA ARINA GHERGHESCU2* \\ ${ }^{1}$ Politehnica University of Bucharest, Materials Science and Engineering Faculty, Department of Metallic Materials Processing \\ and Eco - Metallurgy , 313 Splaiul Independentei, 060042, Bucharest, Romania \\ 2 Politehnica University of Bucharest, Materials Science and Engineering Faculty, Department of Materials Science and Physical \\ Metallurgy, 313 Splaiul Independentei, 060042 Bucharest, Romania
}

The paper presents cavitation erosion testing results of three stainless steels that may be used in making hydropower turbine parts. Two of these steels have a chemical composition close to that of some other stainless steels previously employed in producing these parts. They are updated steel grades of the former ones. The third one is newly conceived. Aiming better mechanical and corrosion resistance characteristics as well as an inclusion - free structural state, steels were produced in an induction furnace with cold copper crucible under vacuum and argon atmosphere. Quenching and tempering heat treatments were subsequently applied.

Keywords: cavitation erosion, turbine runner blade, new martensitic steel, maraging steel

Erosion is the phenomenon consisting in damaging the oxide layer of a material surface caused by high-speed abrasive flow of a fluid. The process of removing the protective film from the surface is finished by corrosion. Erosion and corrosion are often accelerated by turbulent fluid flows, fluid corrosivity, the existence of a biphasic flow (such as steam and water), or a flow with suspended solids within the fluid [1].

Stainless steels, nickel and titanium alloys exhibit a passive surface film more resistant than that of other metallic materials, this feature being a factor in choosing a high erosion-corrosion resistant material.

Cavitation means formation of bubbles or cavities in a liquid, due to the reduction of local pressure of the liquid. When falling below a critical value, bubbles will form. When these bubbles face a high local pressure they will implode, generating microjets or shock waves [2]. If bubble implosions occur near a solid surface, these microjets or shock waves will exert intense pressure on it. After such repeated events, the attacked surface area will suffer fatigue and rupture with material losses. This phenomenon is known as cavitation erosion (CE).

Cavitation corrosion is a particular form of erosion caused by the implosion of gas bubbles on a metal surface. These phenomena increase the corrosion rate of a piece by destroying the protective film or layer at its surface. When cavitation occurs in a corrosive environment, erosioninduced corrosion and / or corrosion - induced erosion will intensify the deterioration process and may be termed corrosion - erosion cavitation $[3,4]$.

The cavitation resistance of a material has to be considered as an independent property of the material, stand alone and not derived from other properties [2].

In order to reduce CE, three options can be approached concurrently: improving design to minimize large hydrodynamic pressure differences; changing environmental conditions, for example, temperature and corrosivity of fluids; selecting more resistant materials or applying a protective layer. Unfortunately, changing designs and controlling environmental conditions are not easy options, while the third approach is easier to achieve.
Generally, the criteria for selecting CE - resistant materials include hardness, martensitic transformability (low energy packing lowstacking) for cavitation energy absorption and corrosion resistance [5].

Turbine rotor blades (runner blades) are subjected to cavitation damage. Such damage will result in loss of pumping capacity and eventually in catastrophic effects on the pump rotor. The erosion rate is higher for hydraulic turbines operating in sand water $[6,7]$.

Stainless steels are used in manufacturing hydropower runner blades. A selection between austenitic and martensitic steels may be made on requirements such as high hardness and good corrosion resistance of the runner blades.

Martensitic steels ( $\mathrm{Cr}<16 \%, \mathrm{Ni}=2-6 \%, \mathrm{C}=0.1-0.5$ $\%)$ are the first choice but their corrosion resistance is not high enough [8,9]. They are favoured in respect of conferring a higher hardness to the runner blade material by exhibiting a microstructure containing precipitates, by increasing the welding capability through nickel addition and reduction of carbon content.

Austenitic steels $(\mathrm{Cr}=16-28 \%, \mathrm{Ni}=8-30 \%, \mathrm{C}<0.1$ $\%)$ show higher corrosion resistance, weldability, plasticity and creep resistance but weaker mechanical properties. Aiming to increase the latter, a partial substitution of $\mathrm{Ni}$ with gammageneous elements such as $\mathrm{Mn}$ and $\mathrm{N}$ is needed, but leading to a corrosion resistance reduction.

Duplex steels (ferrito-austenitic) exhibit higher traction and fatigue resistance, better weldability and corrosion resistance under load, satisfactory corrosion resistance and lower cost than austenitic ones due to lower Ni content (1.4 - $7 \%$ ) [10,11]. The aim is to increase the corrosion resistance of these alloys by adding Mo $(0.3-4 \%)$, and increasing the tensile strength by nitrogen addition. These alloying elements may confer a better hardness in the entire volume (Mo, N) or in surface only $(\mathrm{N})$ and may be involved in the passivation-repassivation phenomenon during cavitation attacks (Mo) $[12,13]$.

Steel making in an induction furnace with cold copper crucible was performed. A new stainless steel for hydropower turbine was conceived, also made in an 
induction furnace, this steel making method providing better material structural characteristics.

\section{Experimental part}

Steels were made in an induction furnace with a cold copper crucible with an inner diameter of $35 \mathrm{~mm}$ and a capacity of $8-15 \mathrm{~cm}^{3}$ equipped with a casting plug. The working parameters of the furnace are: nominal power 25 $\mathrm{kW}$, frequency HF $100-400 \mathrm{kHz}$, apparent power $40 \mathrm{kVA}$, phase current $40 \mathrm{~A}$, power factor 0.92 , minimum water flow $12 \mathrm{l} / \mathrm{min}$, maximum inlet pressure: $7.5 \mathrm{bar}$, water inlet: $\max .24^{\circ} \mathrm{C}$, maximum working temperature of $2800^{\circ} \mathrm{C}$.

Two formerly stainless steels used in manufacturing runner blades for hydropower turbines located on river OIt, Romania, were T8NCUMC130CS L03.009.0 and GX4CrNi134 (EN 10283). Their chemical compositions determined by optical spectroscopy were presented in table 1 and 2 .

These chemical compositions were also improved and are found in table 3 as P1 and P2 steels, respectively. For P1 steel, Ni content was raised from 1.325 to $4.34 \%$ and the $\mathrm{Cr}$ one was lowered from 13.453 to $11.78 \%$. Other changes were made in order to reach a compromise between the mechanical characteristics and the corrosion resistance behavior of these materials. Copper was not presentin the new chemical compositions. Despite its good influence on the corrosion resistance, the mechanical properties are negatively affected.

The chemical composition of the new P3 steel was established in order to obtain a more resistant steel, suitable to complex requests of the hydropower turbines.

Three steel ingots with the chemical composition shown in table 3 were obtained. P1 and P2 steels have a martensitic - ferritic structure and P3 a martensitic austenitic one, according to Schaeffler diagram [14 ].

In P3 steel, small amounts of Ti $(0.92 w t \%)$, were added [15]. Its chemical composition is close to that of maraging steels, with which it is related. In maraging steels $\mathrm{Ti}$ is present because it favors the precipitation of $\mathrm{Ni}_{3} \mathrm{Ti}$ compounds which generate the highest hardening effect $[16,17]$.

Ti should be added in a small quantity because the hardening mechanism induces high internal stresses on the crystalline level, which could negatively influence the corrosion resistance of the new designed steel. Furthermore, a Ti addition is highly requested, because it activates the formation of $\mathrm{Ni}_{3} \mathrm{Mo}$ compound, which gives a slightly diminished hardening effect but does not strongly impair the corrosion resistance. Precipitation consists in the mixed $\mathrm{Ni}_{3}(\mathrm{Ti}, \mathrm{Mo})$ compound $[16,17]$.

Considering all these data, the choice was made for a minimum value of $\sim 0.9 \mathrm{wt} \% \mathrm{Ti}$. Three batches, P1, P2, $\mathrm{P} 3$, were thus obtained having the chemical compositions presented in table 3. 4).

Samples were submitted to the heat treatments (table

Samples obtained from P1, P2 and P3 steels will be thus termed samples 1, 2 and 3.

Cavitation erosion resistance of the selected materials were tested by the vibration method which has the advantages of short testing times and easy comparison of results.

The experiments performed at the ECOMET Center, PolytechnicUniversity of Bucharest were made using a modified version of the ASTM G32 standardized method on a piezoelectric crystal system. The change consists in positioning the specimen at a distance of $0.5-0.7 \mathrm{~mm}$ from the end of the sonotrode, the sample being not attached to it. The method is denominated indirect vibration or stationary sample vibration method.

The major disadvantage of the stationary sample vibration method, as against to the vibration method with the sample attached to the sonotrode [18], is the reduced intensity of the cavitation erosion, leading to higher testing times. To obtain the same eroded mass by both methods, testing time for the stationary sample method must be approximately five times higher than the first.

The cavitation erosion testing setup consists of the following systems: Hielscher UP200St electronic ultrasonic generator; oscillation system; vessel for the cavitant fluid provided with copper spiral cooling system continuously cooled with water.

Table 1

CHEMICAL COMPOSITION OF RUNNER BLADE STEEL NO.1 (FACTORY STEEL GRADE)

\begin{tabular}{|l|c|c|c|c|c|c|c|c|c|c|}
\hline \multirow{2}{*}{ Factory steel grade } & \multicolumn{10}{|c|}{ Content, wt \% } \\
\cline { 2 - 12 } & $\mathrm{C}$ & $\mathrm{Si}$ & $\mathrm{Mn}$ & $\mathrm{P}$ & $\mathrm{S}$ & $\mathrm{Cr}$ & $\mathrm{Ni}$ & $\mathrm{Mo}$ & $\mathrm{Cu}$ & $\mathrm{V}$ \\
\hline Runner blade 1 & 0.074 & 0.332 & 0.595 & 0.016 & 0.022 & 13.453 & 1.325 & 0.066 & 1.295 & 0.029 \\
\hline T8NCuMC130 CS & $\max$. & $\max$. & $0.2 \div$ & $\max$ & $\max$ & $12.0 \div$ & $1.0 \div$ & - & $1.0 \div$ & - \\
L03.009.0 & 0.10 & 0.4 & 0.6 & 0.025 & 0.030 & 13.5 & 1.5 & - & 1.3 & - \\
\hline
\end{tabular}

Table 2

CHEMICAL COMPOSITION OF RUNNER BLADE STEEL NO.2 (FACTORY STEEL GRADE)

\begin{tabular}{|c|c|c|c|c|c|c|c|c|c|c|c|}
\hline \multirow{2}{*}{$\begin{array}{c}\text { Factory steel } \\
\text { grade }\end{array}$} & \multicolumn{9}{|c|}{ Content, wt \% } \\
\cline { 2 - 12 } & $\mathrm{C}$ & $\mathrm{Si}$ & $\mathrm{Mn}$ & $\mathrm{P}$ & $\mathrm{S}$ & $\mathrm{Cr}$ & $\mathrm{M}$ N & $\mathrm{Ni}$ & $\mathrm{V}$ & $\mathrm{Al}$ & $\mathrm{Cu}$ \\
\hline Runner blade 2 & 0.025 & 0.40 & 0.73 & 0.035 & 0.002 & 12.60 & 0.35 & 3.82 & 0.03 & 0.012 & 0.35 \\
\hline G-X4CrNi13-4 & $<0.06$ & $<1$ & $<1$ & $<0.035$ & $<0.025$ & $12-$ & $0.4-1$ & $3.5-$ & - & - & - \\
& & & & & & 13.5 & & 4.5 & & & \\
\hline
\end{tabular}

Table 3

CHEMICAL COMPOSITIONS IN WT\% OF P1, P2 AND P3 STEELS

\begin{tabular}{|c|c|c|c|c|c|c|c|c|c|c|c|c|c|c|c|}
\hline & $\mathrm{Cr}$ & $\mathrm{Ni}$ & Mo & $\mathrm{Si}$ & $\mathbf{C u}$ & Mn & $\mathrm{Ti}$ & Al & $\mathbf{N b}$ & C & $\mathbf{V}$ & $\mathrm{Co}_{0}$ & $\mathbf{P}$ & S & $\mathrm{Fe}$ \\
\hline P1 & 11.78 & 4.34 & 0.002 & 0.182 & 0.078 & 0.550 & 0.001 & 0.0061 & 0.012 & 0.042 & 0.025 & 0.016 & 0.0079 & 0.0085 & 82.95 \\
\hline $\mathrm{P} 2$ & 12.05 & 3.85 & 1.024 & 0.393 & 0.170 & 0.676 & 0 & 0.0282 & 0.0438 & 0.0426 & 0.0081 & 0.0299 & 0.0287 & 0.0114 & 81.64 \\
\hline P3 & 9.92 & 9.61 & 5.07 & 0.295 & 0.147 & 0.351 & 0.923 & 0.049 & 0.0889 & 0.0223 & 0.0022 & 0.0356 & 0.0204 & 0.0204 & 73.8 \\
\hline
\end{tabular}

\begin{tabular}{|c|c|c|}
\hline & Quenching temperature, ${ }^{\circ} \mathrm{C}$ & Tempering (ageing) temperature, ${ }^{\circ} \mathrm{C}$ \\
\hline P1 & 1000 & 700 \\
\hline P2 & 1000 & 700 \\
\hline P3 & 1000 & 480 \\
\hline
\end{tabular}

Table 4

TEMPERATURES OF HEAT TREATMENTS PERFORMED ON THE THREE STE 
The working parameters were those provided by the ASTM G32-10 standard: working frequency, $f=20 \mathrm{kHz}$; amplitude on the surface of the specimen: $A=50 \mu \mathrm{m}$; liquid temperature: $24-26^{\circ} \mathrm{C}$.

Cavitation resistance testing was performed using a Hielscher UP 200St ultrasonic probe according to the G32 standard with a total cavitation testing time of $6 \mathrm{~h}$. The samples were mounted on a support to ensure the stability and parallelism between their surface and the probe surface and submitted to ultrasonic vibration during several cycles of 30 min time. Their weight was measured before and after each cycle. The working environment was water at a constant temperature of $22^{\circ} \mathrm{C}$. The specimens were positioned at a distance of $0.5 \mathrm{~mm}$ from the end of the sonotrode.

Characterization of cavitation erosion damage was achieved by plotting the diagrams of the eroded mass and the cavitation erosion rate versus time, by atomic force microscopy (AFM) on a NANONICS IMAGING MultiView 4000SPM/NSOM microscope in order to characterize the topography of surfaces damaged by cavitation, and scanning electron microscopy (SEM) on a FEl Quanta 450 FEG microscope to highlight the effects of the cavitation phenomenon on the surface integrity of the tested materials.

\section{Results and discussions}

Cavitation erosion results

Tables 5 to 7 show the results of the cavitation erosion tests performed on samples 1, 2 and 3. The total testing time was $360 \mathrm{~min}$. Variations of the eroded mass and the cavitation erosion rate versus time are shown in figures 1 to 8 .

Sample 1

Table 5

CAVITATION EROSION MEASUREMENTS FOR SAMPLE 1

\begin{tabular}{|c|c|c|c|c|c|c|c|c|}
\hline $\mathrm{t}$ & $\Delta \mathrm{em}$ & $r_{c e}$ & $\mathrm{t}$ & $\Delta \mathrm{em}$ & $\mathrm{r}_{60}$ & $t$ & $\Delta \mathrm{em}$ & $\mathrm{r}_{\infty}$ \\
\hline$[\mathrm{min}]^{-}$ & [mg] & {$[\mathrm{mg} / \mathrm{min}]$} & {$[\mathrm{min}]$} & [mg] & [mg/min] & {$[\mathrm{min}]^{-}$} & [mg] & {$[\mathrm{mg} / \mathrm{min}]$} \\
\hline 0 & 0 & 0 & 150 & 0.42 & 0.0028 & 300 & 3.22 & 0.0107 \\
\hline 30 & 0.07 & 0.0023 & 180 & 0.94 & 0.0052 & 330 & 3.55 & 0.0108 \\
\hline 60 & 0.17 & 0.0028 & 210 & 1.72 & 0.0082 & 360 & 3.82 & 0.0105 \\
\hline 90 & 0.23 & 0.0026 & 240 & 2.66 & 0.0108 & & & \\
\hline 120 & 0.31 & 0.0025 & 270 & 2.94 & 0.0109 & & & \\
\hline
\end{tabular}

Eroded mass vs. time, sample 1

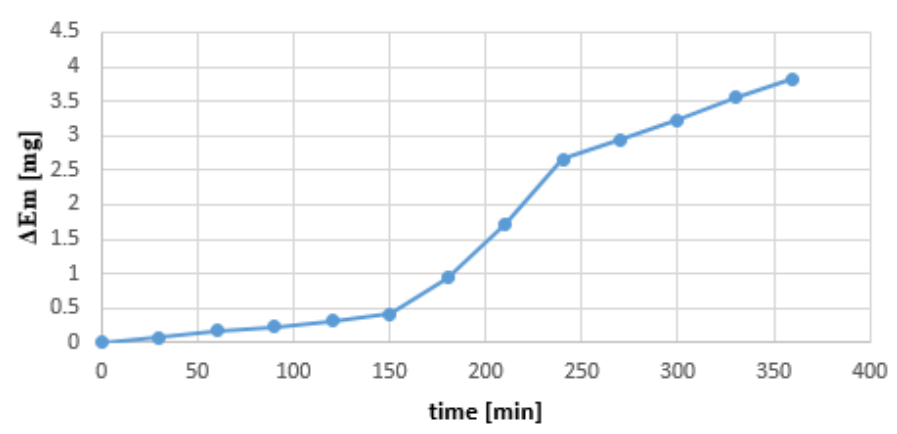

Cavitation erosion rate vs. time, sample 1

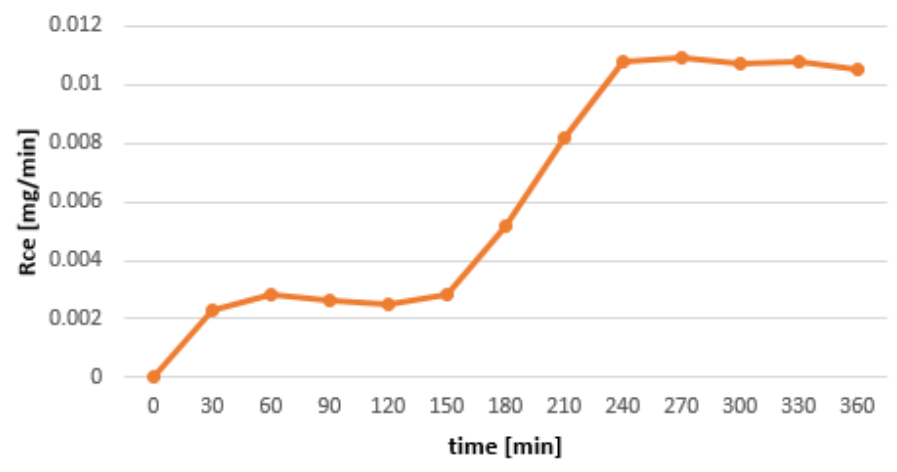

From the evolution of eroded mass and cavitation erosion rate versus time performed on sample 1 , it was found that all along the testing cycle the eroded mass was about $3.8 \mathrm{mg}$. Its variation exhibits a non-uniform evolution along the $360 \mathrm{~min}$. Thus, in the first 150 min we have a relatively constantincrease in the eroded mass, then for the next 100 min the increase is
Fig. 1. Variation of eroded mass vs. time in sample 1

Fig. 2. Variation of cavitation erosion rate vs. time for sample 1 
Table 6

CAVITATION EROSION MEASUREMENTS FOR SAMPLE 2

\begin{tabular}{|c|c|c|c|c|c|c|c|c|}
\hline $\mathrm{t}$ & $\Delta \mathrm{em}$ & $\mathrm{r}_{\mathrm{ce}}$ & $\mathrm{t}$ & $\Delta \mathrm{em}$ & $\mathrm{r}_{\mathrm{ce}}$ & $\mathrm{t}$ & $\Delta \mathrm{em}$ & $\mathrm{r}_{\mathrm{co}}$ \\
\hline$[\mathrm{min}]$ & {$[\mathrm{mg}]$} & {$[\mathrm{mg} / \mathrm{min}]$} & {$[\mathrm{min}]$} & {$[\mathrm{mg}]$} & {$[\mathrm{mg} / \mathrm{min}]$} & {$[\mathrm{min}]$} & {$[\mathrm{mg}]$} & {$[\mathrm{mg} / \mathrm{min}]$} \\
\hline 0 & 0.00 & 0.0 & 150 & 1.77 & 0.0118 & 300 & 3.10 & 0.0103 \\
\hline 30 & 0.33 & 0.011 & 180 & 2.17 & 0.0121 & 330 & 3.35 & 0.0101 \\
\hline 60 & 0.78 & 0.013 & 210 & 2.32 & 0.011 & 360 & 3.64 & 0.0101 \\
\hline 90 & 1.14 & 0.0127 & 240 & 2.58 & 0.0104 & & & \\
\hline 120 & 1.53 & 0.0125 & 270 & 2.86 & 0.0106 & & & \\
\hline
\end{tabular}

Eroded mass vs. time, sample 2

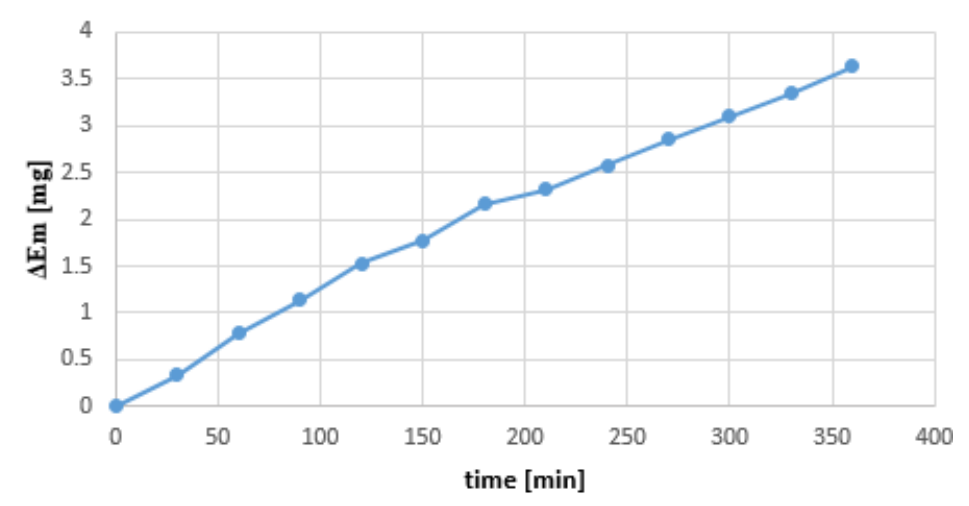

Fig. 3. Variation of eroded mass vs. time in sample 2

Cavitation erosion rate vs. time, sample 2

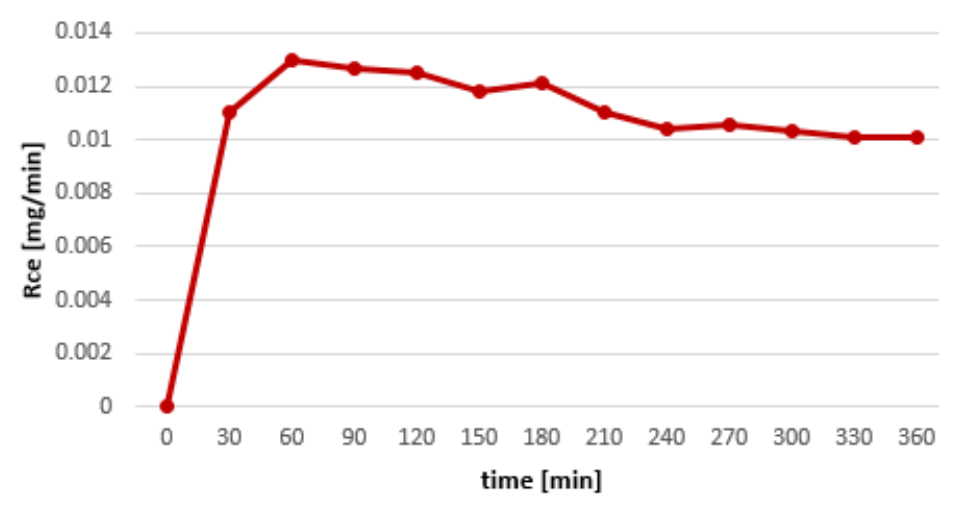

Fig. 4. Variation of cavitation erosion rate vs. time for sample 2

From the analysis of the graphs representing the evolution of the eroded mass and cavitation erosion rate versus time for sample 2 one can see that it is different as against that of sample 1. For the whole testing cycle the eroded mass was approximately $3.6 \mathrm{mg}$. Mass variation shows a relatively constant evolution along the $360 \mathrm{~min}$. Thus, after the first 30 min testing time we have an loss of roughly $0.3-0.4 \mathrm{mg} / 30$ min for the entire duration of the test.

Another difference as against sample 1 is that the corrosion rate has a maximum value at the beginning of the test, after which it is slightly decreasing but still remains around the maximum value. During the test, maximum values of about $0.013 \mathrm{mg} / \mathrm{min}$ were recorded.

Sample 3
From the analysis of the diagram representing the evolution over time of the eroded mass and the cavitation erosion rate performed on sample 3 , it was found that along the whole testing cycle the eroded mass was about 0.7 $\mathrm{mg}$. Compared to the first two samples, this one has a much lower value of the eroded mass. Its variation shows a relatively constant evolution over the $360 \mathrm{~min}$. Thus, for each 30 min interval, we have an increment of $0.1 \mathrm{mg}$ for the entire duration of the test, values that are also lower than for the first two samples.

A resemblance with sample 2 consists in that the corrosion rate has a sharp increase in the firstfew minutes, then a smaller increase, and towards the end of the testing interval the erosion

Table 7

CAVITATION EROSION MEASUREMENTS FOR SAMPLE 3

\begin{tabular}{|c|c|c|c|c|c|c|c|c|}
\hline$t$ & $\Delta \mathrm{em}$ & $r_{c e}$ & $t$ & $\Delta \mathrm{em}$ & $\mathrm{r}_{50}$ & $t$ & $\Delta \mathrm{em}$ & $\mathrm{r}_{\infty}$ \\
\hline [min] & [mg] & {$[\mathrm{mg} / \mathrm{min}]$} & {$[\mathrm{min}]$} & [mg] & {$[\mathrm{mg} / \mathrm{min}]$} & [min] & [mg] & {$[\mathrm{mg} / \mathrm{min}]$} \\
\hline 0 & 0.0 & 0.0 & 150 & 0.43 & 0.0029 & 300 & 0.66 & 0.0022 \\
\hline 30 & 0.08 & 0.0027 & 180 & 0.49 & 0.0027 & 330 & 0.69 & 0.0021 \\
\hline 60 & 0.17 & 0.0028 & 210 & 0.51 & 0.0024 & 360 & 0.72 & 0.0019 \\
\hline 90 & 0.29 & 0.0032 & 240 & 0.55 & 0,0020 & & & \\
\hline 120 & 0.41 & 0.0033 & 270 & 0.60 & 0.0022 & & & \\
\hline
\end{tabular}


Eroded mass vs. time, sample 3

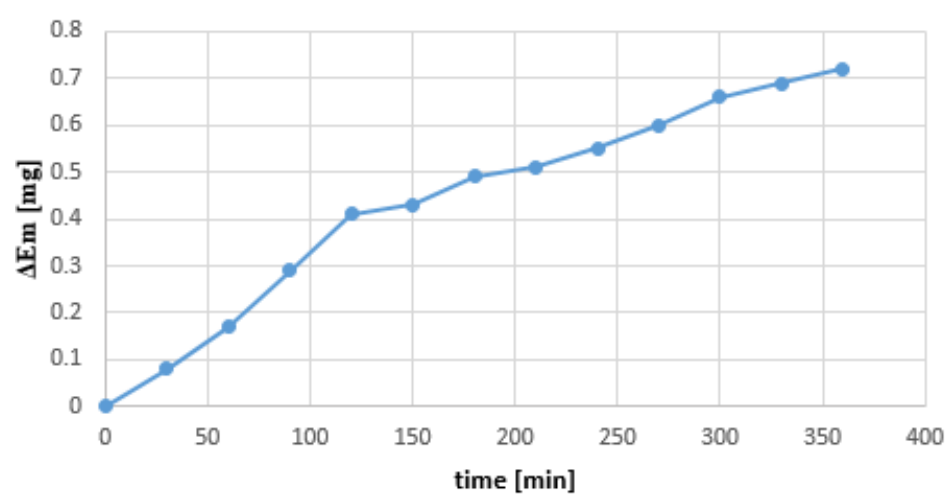

Fig. 5. Variation of eroded mass vs. time in sample 3

Cavitation erosion rate vs. time, sample 3

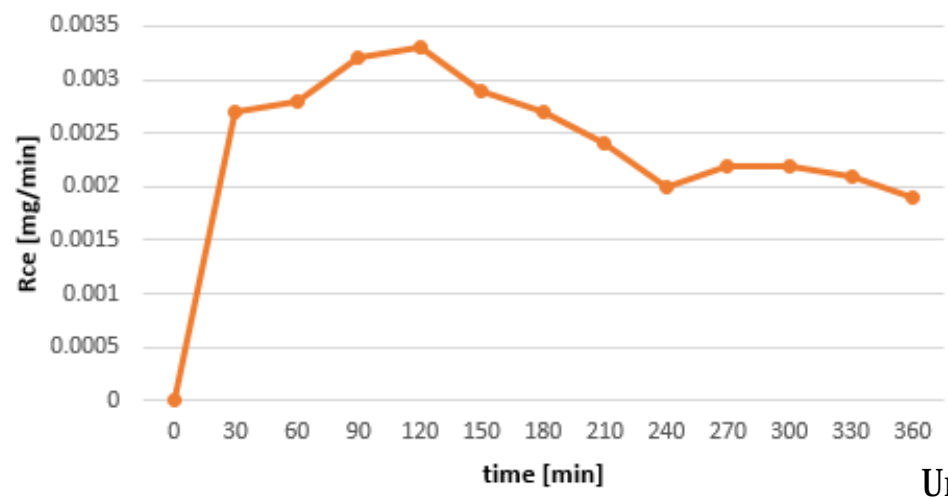

Fig. 6. Variation of cavitation erosion rate vs. time for sample 3

rate has a downward trend. As a difference, in sample 3 maximum values of roughly $0.003 \mathrm{mg} / \mathrm{min}$ have been recorded during the test as against $0.01 \mathrm{mg} / \mathrm{min}$, representing values of the first two samples.

Putting together the variation of the eroded mass curves (fig. 7) one can see that sample 2 has the highest values and exhibits a constant evolution, then sample 1 has a relatively good evolution in the first half of the test after which it yields and reaches the same values as sample 2 .

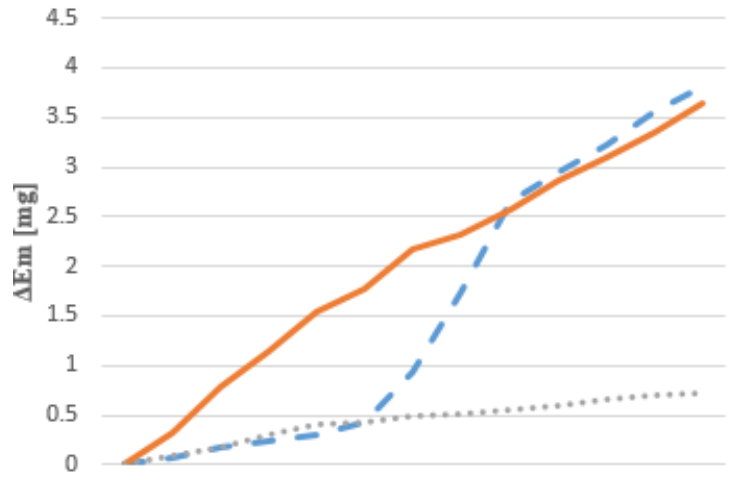

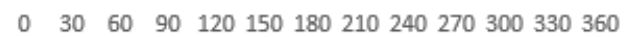
time [min]

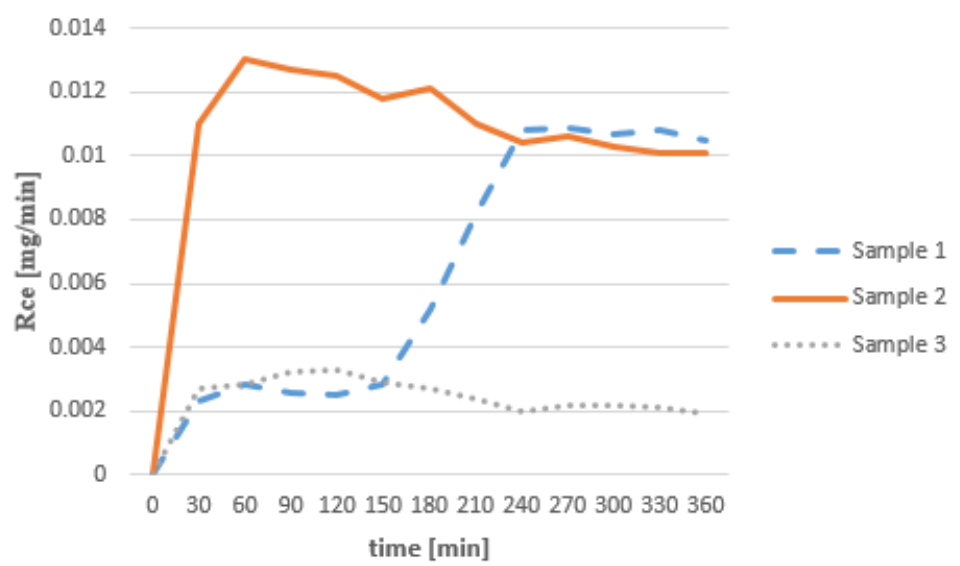

Fig. 7. Variation of eroded mass vs. time in samples 1,2 and 3 ike the first two samples, sample 3 shows a constant evolution of the eroded mass from the beginning of the test to the end, but with much lower values than the other samples, which are characteristic for a better resistance to cavitation erosion.

As for the three superimposed curves representing the cavitation erosion rates seen in figure 8 on the same graph, one can easily see that sample 2 has the highest values, followed by sample 1 which has a very good resistance in the first half of the testing time after which it yields and reaches the same values as sample 2 . Unlike the first two 
samples, sample 3 shows a very low cavitation erosion rate at the start of the test and tends to show decreasing values, being superior when it comes to cavitation erosion resistance as against samples 1 and 2 .

\section{Analysis of cavitation erosion samples surfaces byscanning} electron microscopy (SEM)

For a comparative analysis of the surfaces of the three samples subjected to cavitation, a scanning electron microscopyanalysis was performed. The results are shown in figure 9.

Figure 9 shows surfaces features of sample 1 after cavitation resistance testing from $100 \mathrm{x}$ to $10000 \mathrm{x}$ magnification. The surface area of sample 1 material is highly impaired as compared to sample 3. Material ruptures and cracks may easily be observed.

Sample 2 also exhibits a more pronounced deterioration when compared to sample 3 but its aspect is better than sample 1 at the end of the $6 \mathrm{~h}$ cavitation resistance test.
SEM examination of sample 3 highlights the effects of the cavitation phenomenon on the material surface. When compared with the other two samples it is found that sample 3 is the most resistance to cavitation erosion under same testing conditions. At small magnifications sample 3 surface is very little changed. At higher magnifications the same phenomenon of local fractures, cracks and craters formation is observed but at a lower level than in samples 1 and 2 .

Considering these aspects, the SEM analysis demonstrates that all three materials are suitable for use in environments involving the cavitation phenomenon occurrence but among them, sample 3 performs best with the leastaffected structure.

Analysis by AFM microscopy of sample surfaces subjected to cavitation erosion

To relieve the dimensions of the surface craters, the three samples subjected to the cavitation erosion process were analyzed byAFM microscopy, the results being shown in figures 10 to 18.
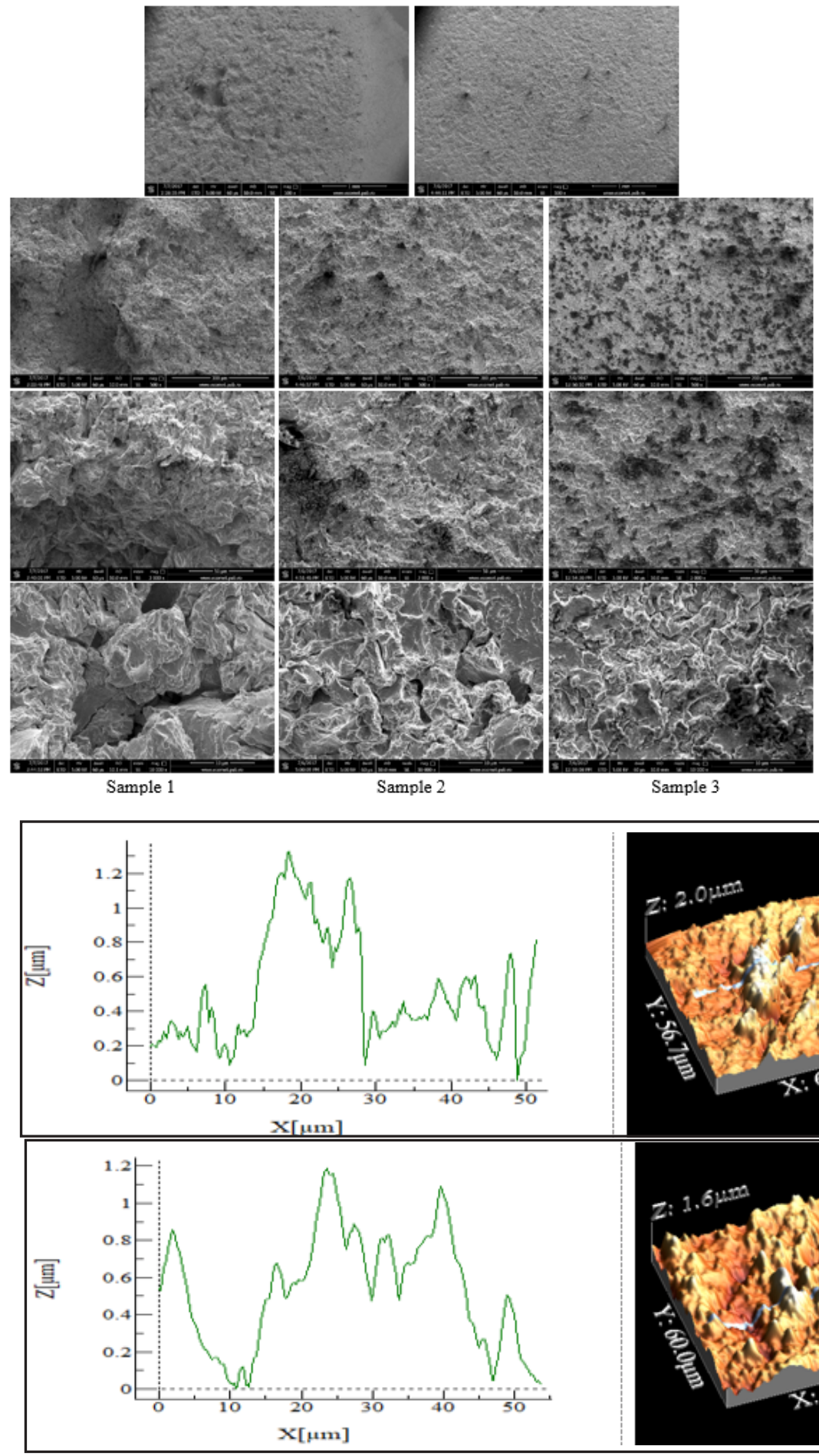

Fig 9. SEM images of samples 1,2 and 3 surfaces at 100x, 500x, 2000x and 10.000x magnifications
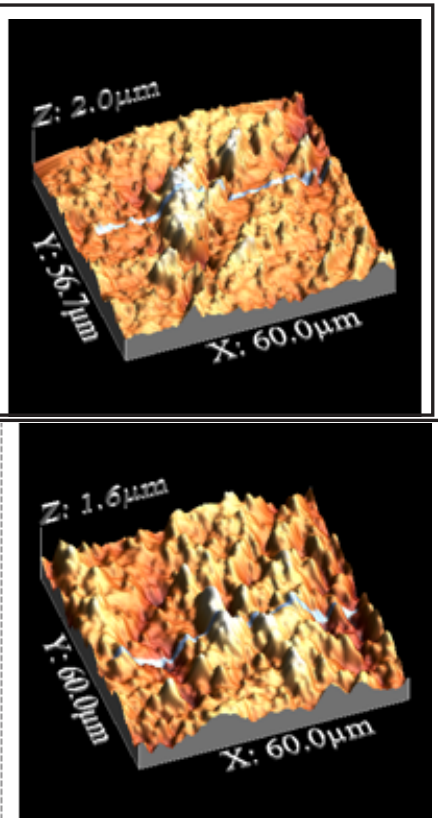

Fig. 10. Cross - sectional profile and 3D topography AFM images of the investigated sample 1 , cavitation erosion testing time $=2 \mathrm{~h}$.

Fig. 11. Cross - sectional profile and 3D topography AFM images of the investigated sample 1 , cavitation erosion testing time $=4 \mathrm{~h}$. 


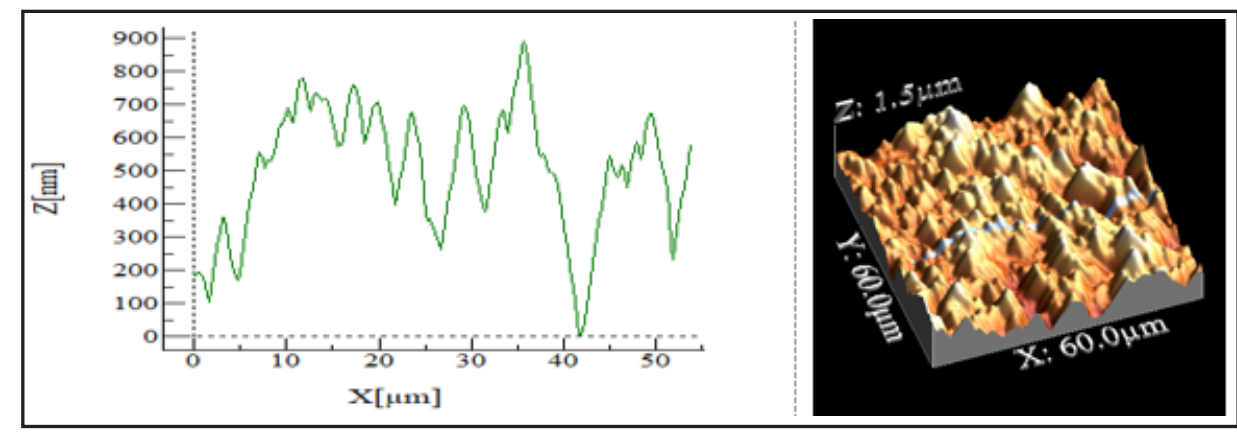

Fig. 12. Cross - sectional profile and 3D topography AFM images of the investigated sample 1, cavitation erosion testing time $=6 \mathrm{~h}$

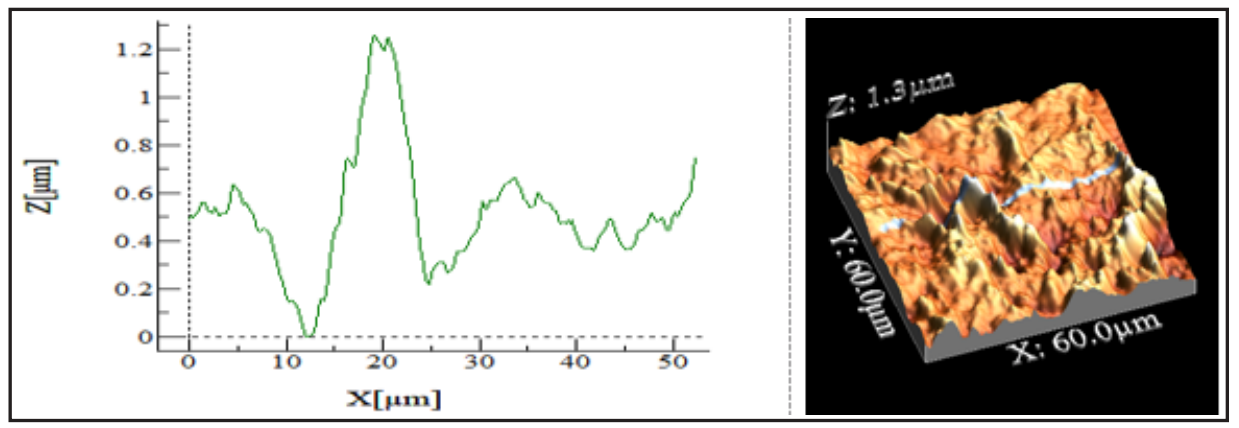

Fig. 13. Cross - sectional profile and 3D topography AFM images of the investigated sample 2 , cavitation erosion testing time $=2 \mathrm{~h}$.

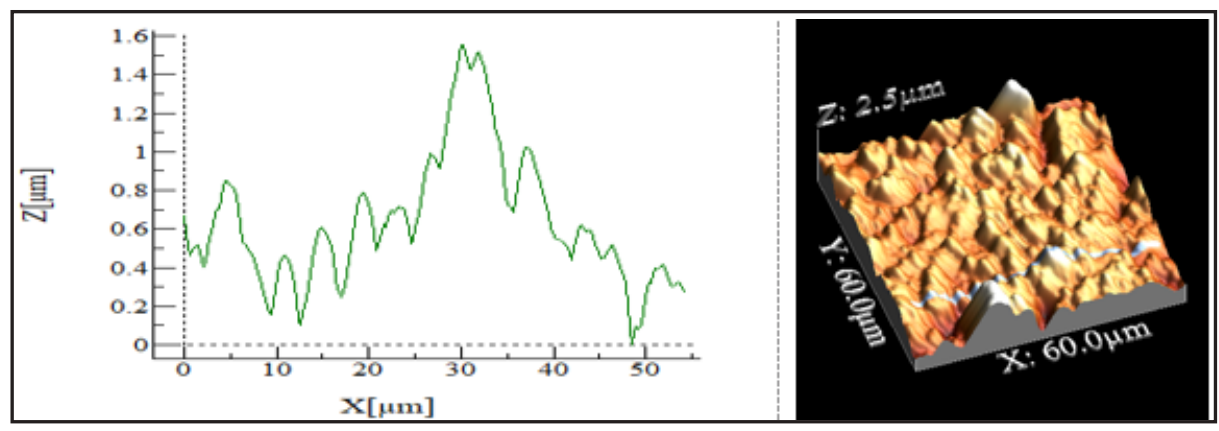

Fig. 14. Cross - sectional profile and 3D topography AFM images of the investigated sample 2, cavitation erosion testing time $=4 \mathrm{~h}$.

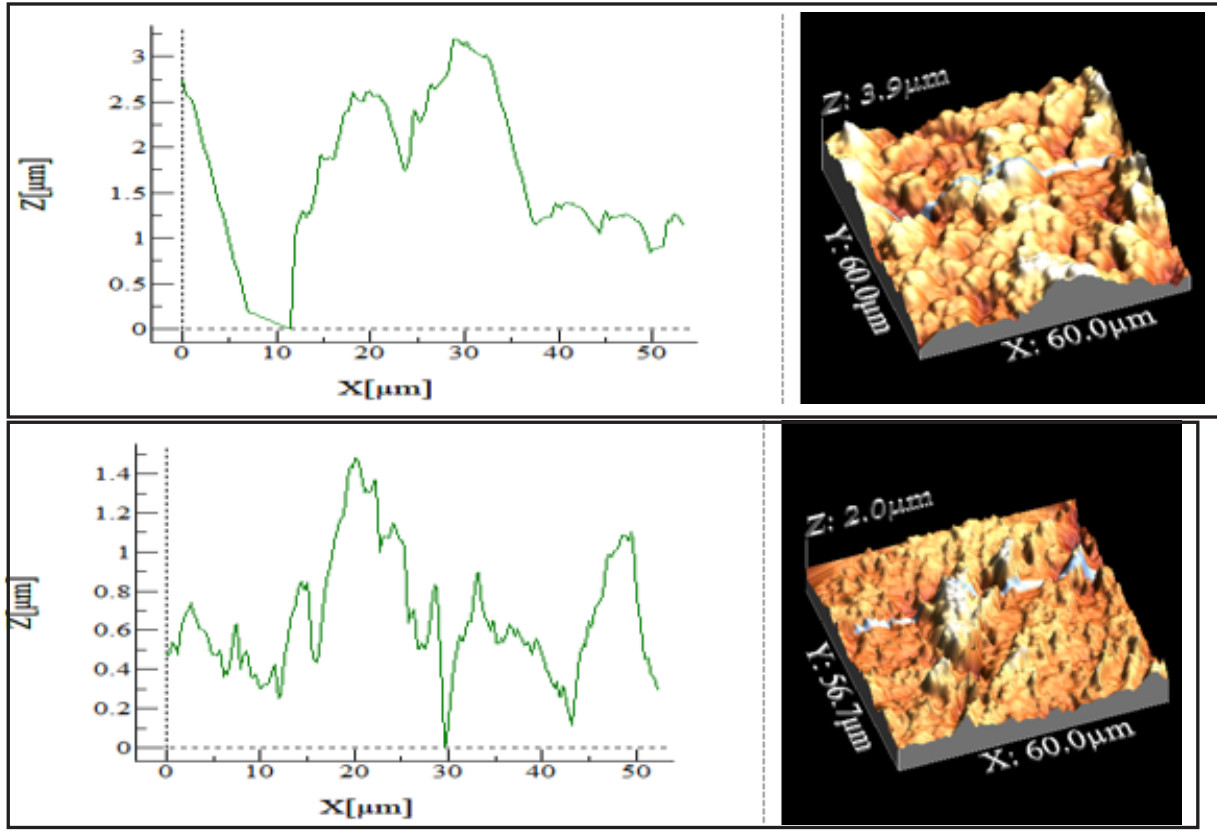

Fig. 15. Cross - sectional profile and 3D topography AFM images of the investigated sample 2, cavitation erosion testing time $=6 \mathrm{~h}$.

Fig. 16. Cross - sectional profile and 3D topography AFM images of the investigated sample 3 , cavitation erosion testing time $=2 \mathrm{~h}$.

Fig. 17. Cross - sectional profile and 3D topography AFM images of the investigated sample 3, cavitation erosion

$$
\begin{aligned}
& \text { testing } \\
& \text { time }=4 \mathrm{~h}
\end{aligned}
$$



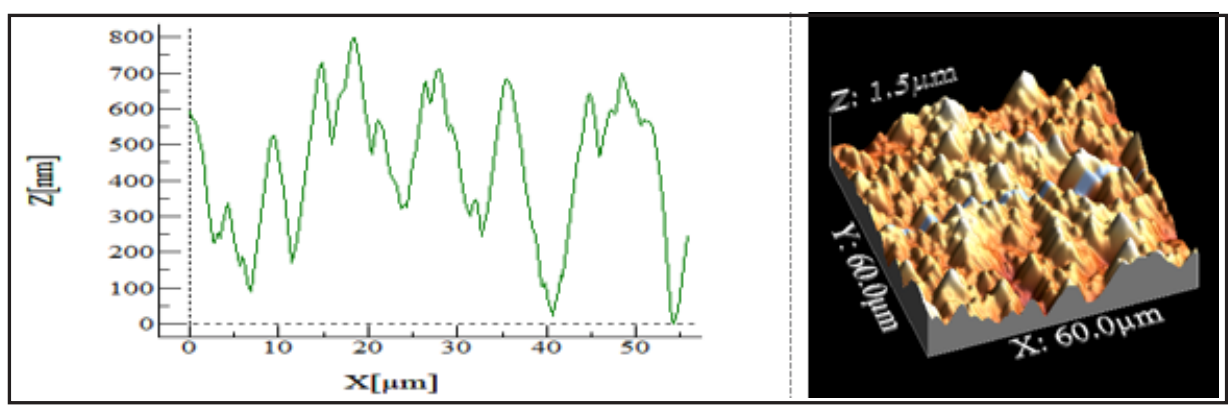

Fig. 18. Cross - sectional profile and 3D topography AFM images of the investigated sample 3 , cavitation erosion testing time $=6 \mathrm{~h}$.

Table 8

SAMPLES AVERAGE ROUGHNESS (SAR), $\mu \mathrm{m}$

\begin{tabular}{|c|c|c|c|c|}
\hline & Sample / Time & 2 & 4 & 6 \\
\hline \multirow{3}{*}{$\begin{array}{c}\text { SAR, } \\
\mu \mathrm{m}\end{array}$} & Sample 1 & 0.273 & 0.2356 & 0.221 \\
\cline { 2 - 5 } & Sample 2 & 0.1703 & 0.3149 & 0.5971 \\
\cline { 2 - 5 } & Sample 3 & 0.23 & 0.222 & 0.198 \\
\hline
\end{tabular}

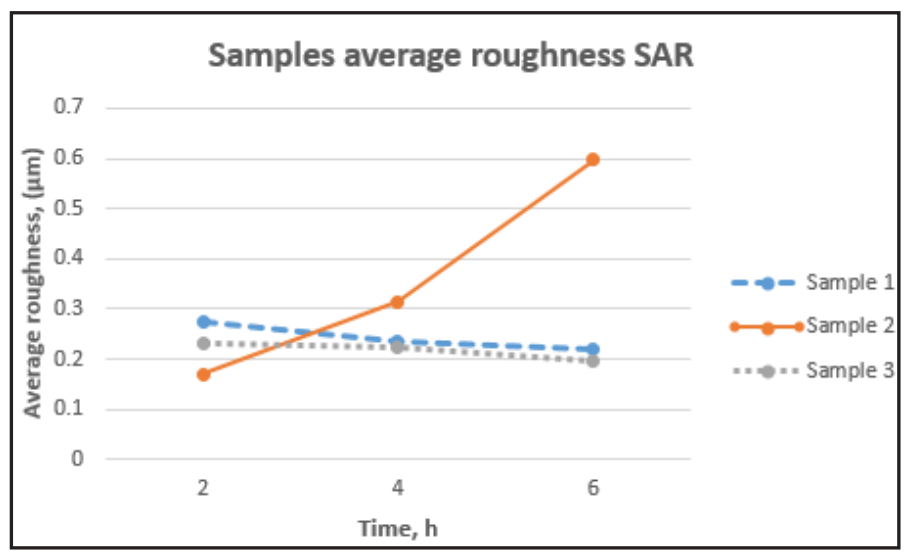

Using the Atomic Force Microscope (AFM), the sample surfaces were analyzed at three different moments of time along the cavitation attack. The samples were examined by the non-contact method in which the tip of the AFM sample did not come into direct contact with the analyzed surface. The assay area was of approximately $60 \mu \mathrm{m}^{2}$ at a $10 \mathrm{~ms}$ analysis time.

For sample 1 a gradual decrease in surface roughness due to deterioration and a stabilization tendency by reducing the level differences between the maximum and the minimum surface height may be observed.

Sample 2 shows an increased damage over the other two samples and a significant increase in roughness is observed. This phenomenon shows an intensification as the cavitation erosion process reaches to its end.

For sample 3 the same surface stabilization tendency that gives better cavitation erosion resistance as well as lower roughness than sample 1 is observed. It can be seen that the maximum height of the sample 3 surface roughness reached after 6 hours of erosion is about $800 \mathrm{~nm}$, while for sample 1 under the same conditions it is of $900 \mathrm{~nm}$.

From AFM surface images and roughness analyses one can see that sample 3 exhibits a high cavitation erosion resistance and a high tendency to form a smooth and stable surface during the erosion attack.

\section{Conclusions}

Cavitation erosion surface testing of the three steel samples was performed using a modified version of the standardized ASTM G32 method on a piezoelectric crystal system also referred to as indirect vibration method or stationary sample vibration method. Characterization of cavitation erosion intensity was made by plotting the eroded mass and cavitation erosion rate versus time. Atomic force microscopy was chosen to characterize the cavitated surface 3D topography, and SEM to highlight the effects of cavitation phenomena on the surface integrity of the tested materials.

Analysis of AFM microscopy after the cavitation process revealed in sample 1 a gradual decrease in surface roughness due to cavitation erosion damage and a tendency to surface stabilization indicated by a drop of

Fig. 19. Evolution of cavitated surface roughness vs. time ELS

level differences between the surface maximum and minimum height points.

Sample 2 shows a higher cavitation erosion as against the other two samples. A significant increase in roughness is observed, with an intensity ascending in time along the whole test duration.

For sample 3, the same surface stabilization tendency that gives cavitation erosion resistance as well as a lesser roughness as against sample 1 is observed. It can be seen that the maximum height of surface roughness reached by sample 3 after $6 \mathrm{~h}$ of testing is about $800 \mathrm{~nm}$, whereas for sample 1 under the same corrosion conditions the value is $900 \mathrm{~nm}$.

Based on surface and roughness AFM analyses, it can be seen that sample 3 exhibits higher cavitation erosion resistance and tendency to form a smooth and stable surface during cavitation attack.

\section{References}

1.THIRUVENGADAM, A., Proc. of Erosion, Wear and Interfaces of Corrosion, Philadelphia, American Society for Testing and Materials (ASTM), 1974, p.317.

2.KARIMI, A., MARTIN, J.L., INT MATER REV, 31, Issue 1, 1986, p. 18. 3.*** ASTM G119-09, Standard Guide for Determining Synergism between Wear and Corrosion, ASTM, 2009.

4.KWOK, C.T., CHENG, F.T., MAN, H.C., Mater Sci Eng : A, 290, 2000, p.145.

5.KWOK, C.T., MAN, H.C., CHENG, F.T., LO, K.H., SURF COAT TECH, 291, 2016, p.189.

6. IN, H., ZHENG, F., LI, S., HANG, C., WEAR, 112, 1986, p.199.

7.AMARENDRA, H.J., CHAUDHARI, G.P., NATH, S.K. WEAR, 290-291, 2012, p.25.

8.SOHACIU, M., CIUCA, S., SAVASTRU, D., COMAN, G., PREDESCU, A., BERBECARU, A., COTRUT, C., MATEI, E., GHERGHESCU, I.A., PREDESCU, C., OPTOELECTRON ADV MAT, 10, Issue 3-4, 2016, p.259. 9.MATEI, E., PREDESCU, C., BERBECARU, A., PREDESCU, A.M., TRUSCA, R., DIG J NANOMATER BIOS, 6, no. 9, 2011, p. 1701.

10.LUCACCI, G., Materials for Ultra-Supercritical and Advanced UltraSupercritical Power Plant, Woodhead Publishing, DI GIANFRANCESCO, A., 2016, p. 190. 
11.PHANEENDRA, K.C., SHIBU, C., MEASUREMENT, 46, Issue 6, 2013, p. 1880.

12.TANUMA, T., Advances in Steam Turbines for Modern Power Plants, Woodhead Publishing, TANUMA T., 2017, pag. 282.

13.MATEI, E., PREDESCU, A.M., VASILE, E., PREDESCU, C. OPTOELECTRON ADV MAT, 5, Issue 3, 2011, p. 298.

14.SCHAEFFLER, A.L., MET PROG, 56, 11, 1949, p. 680.
15.COMAN, G., CIUCA, S., BERBECARU, A.C., PANTILIMON, M.C., SOHACIU, M.G., GRADINARU, C., PREDESCU, C., U POLITEH BUCH SER B, 79, Issue 4, 2017, p. 213.

16.CARTER, J.C.S., METALL TRANS, 1, 1970, p. 1556.

17.ANTOLOVICH, S., SAXENA, A., CHANANI, C.R., METALL TRANS, 5, 1974, p. 627.

18.BORDEASU, I., MITELEA, I., LAZAR, I., MICU, L. M., KARANCSI, O., Rev. Chim. (Bucharest), 68, no. 12, 2017, p.2914.

Manuscript received: 2.12 .2018 